\title{
Gastric Emptying in Patients With Functional Dyspepsia and Patients With Migraine
}

TO THE EDITOR: I read the paper by Yu et al ${ }^{1}$ entitled "Gastric emptying in migraine: a comparison with functional dyspepsia." The authors measured gastric emptying time in 27 patients with migraine, 32 patients with functional dyspepsia (FD) and 12 healthy controls in order to investigate whether delayed gastric emptying plays a pathogenic role in FD patients or migraine patients without any gastrointestinal symptoms during the interictal periods, and whether delayed gastric emptying is associated with specific dyspeptic symptoms in those patients.

FD is believed to be a heterogeneous disorder in which diverse pathophysiologic mechanisms are involved. Delayed gastric emptying has been considered to be one of the major pathophysiologic mechanisms in FD. ${ }^{2,3}$ A meta-analysis of 17 studies reported that delayed solid gastric emptying was present in about $40 \%$ of patients with FD. ${ }^{4}$ However, larger studies reported delayed gastric emptying in 20-30\% of patients with FD. ${ }^{3}$ The study by $\mathrm{Yu}$ et $\mathrm{al}^{1}$ revealed that the proportions of patients with mildly delayed and delayed gastric emptying were $24.1 \%$ and $58.6 \%$ in the FD group, respectively. The proportion of normal gastric emptying in the FD group was $17.3 \%$. These proportions are very different from those reported in previous studies. The grading criteria of gastric emptying used in that study ${ }^{5}$ should be validated in the author's institution, because the methodology to measure gastric emptying including the type of meal used and a normal range of gastric emptying in asymptomatic healthy controls may be different. Indeed, mildly delayed and delayed gastric emptying were present in $25.0 \%$ and $33.3 \%$ of the healthy controls, suggesting the possibility that the grading criteria of gastric emptying were not appropriate. Regarding the association between gastric emptying parameters and dyspeptic symptoms in patients with $\mathrm{FD}$, small studies have shown controversial results. Whereas, larger studies have shown the association of postprandial fullness and nausea with delayed gastric emptying. 6,7 Because the sample size of the study by $\mathrm{Yu}_{\mathrm{e}} \mathrm{al}^{1}$ is small, it does not have any superiority over the previous studies. The authors failed to find the association of delayed gastric emptying with any dyspeptic symptoms. This negative association might be attributed to the small sample size.

The authors recommended further study for the association of migraine with FD. However, they excluded those who had experienced gastrointestinal symptoms during the interictal period from the migraine group. Upper abdominal symptoms are reported to be more frequent in patients with migraine compared with healthy controls. ${ }^{8}$ Therefore, in order to investigate the association between migraine and $\mathrm{FD}$, it seems to be more rational that migraine patients with upper abdominal symptoms are included in the study. The investigation of the gastric mechanism associated with nausea and vomiting occurring during ictal period is likely to be difficult to perform because gastric function should be measured during ictal period.

Kwang Jae Lee

Department of Gastroenterology, Ajou University Hospital, Ajou University School of Medicine, Suwon, Gyeonggi-do, Korea

1. Yu YH, Jo Y, Jung JY, Kim BK, Seok JW. Gastric emptying in migraine: a comparison with functional dyspepsia. J Neurogastroenterol Motil 2012;18:412-418.

2. Lee KJ, Kindt S, Tack J. Pathophysiology of functional dyspepsia. Best Pract Res Clin Gastroenterol 2004;18:707-716.

3. Tack J, Lee KJ. Pathophysiology and treatment of functional dyspepsia. J Clin Gastroenterol 2005;39(5 suppl 3):S211-S216.

4. Quartero AO, de Wit NJ, Lodder AC, Numans ME, Smout AJ, Hoes AW. Disturbed solid-phase gastric emptying in functional dyspepsia: a meta-analysis. Dig Dis Sci 1998;43:2028- 2033.

5. Abell TL, Camilleri M, Donohoe K, et al. Consensus recommendations for gastric emptying scintigraphy: a joint report of the American Neurogastroenterology and Motility Society and the Society of Nuclear Medicine. J Nucl Med Technol 2008;36:44-54.

6. Stanghellini V, Tosetti C, Paternico A, et al. Risk indicators of delayed gastric emptying of solids in patients with functional dyspepsia. Gastroenterology 1996;110:1036-1042.

7. Sarnelli G, Caenepeel P, Geypens B, Janssens J, Tack J. Symptoms associated with impaired gastric emptying of solids and liquids in 
functional dyspepsia. Am J Gastroenterol 2003;98:783-788.

8. Kurth T, Holtmann G, Neufang-Hüber J, Gerken G, Diener HC.

Prevalence of unexplained upper abdominal symptoms in patients with migraine. Cephalalgia 2006;26:506-510.
Conflicts of interest: None. 